\title{
An Giang: Chủ động, sáng tạo để làm chủ thị trường
}

Hội doanh nghiệp hàng Việt Nam chất lượng cao (HVNCLC) vừa phối hợp với Sở Khoa học và Công nghệ tỉnh An Giang tổ chức hội thảo "Những giải pháp thúc đẩy đổi mới sáng tạo- Bộ cồng cụ đo lường năng lực đổi mới sáng tạo i2Metrix" để chia sẻ những kinh nghiệm thực tế về đổi mới công nghệ và quản trị, định hướng chiến lược kinh doanh, xây dựng kênh phân phối... của các doanh nghiệp (DN) HVNCLC. Từ những chia sẻ này sẽ giúp các $\mathrm{DN}$ xác định năng lực nội tại, định hướng và tìm kiếm những giải pháp để cải thiện, tăng cường sức cạnh tranh và làm chủ thị trường trong tương lai.

\section{Nhiều thành công từ đổi mới sáng tạo}

Doanh nghiệp (DN) cần chủ động đổi mới công nghệ, hoạch định chiến lược sản xuất kinh doanh, tăng khả năng quản trị... là những việc mà các chuyên gia kinh tế khuyến cáo $\mathrm{DN}$ trong hội nhập kinh tế thị trường. Có như vậy, $\mathrm{DN}$ mới đủ sức cạnh tranh với các $\mathrm{DN}$ ngoại cùng ngành hàng và làm chủ thị trường nội địa.

Khách hàng tham quan và tìm hiểu sản phẩm có thành tựu đổi mới sáng tạo tại Hội chợ Hàng Việt Nam chất lượng cao 2014 tại An Giang.

Bà Lê Thị Thanh Lâm, Phó tổng giám đốc Công ty Cổ phần Sài Gòn Food, cho biết: "Thời gian qua, Sài Gòn Food đã tích cực đổi mới sáng tạo bằng việc ứng dụng các tiêu chuẩn đo lường như: ISO, HACCP... để quản lý nguyên vật liệu nhằm hạn chế rủi ro trong quy trình sản xuất. Ngoài ra, Sài Gòn Food còn tập trung đầu tư vào công tác nghiên cứu đưa ra thị trường những sản phẩm mới với chất lượng đảm bảo, giá cả phải chăng. Hiện nhiều sản phẩm của Sài Gòn Food như: lẩu đông lạnh, cháo đóng gói được nhiều người tiêu dùng tin dùng, góp phần đưa tên tuổi Sài Gòn Food đứng vững và không ngừng phát triển trên thị trường". Theo bà Lê Thị Thanh Lâm, đổi mới sáng tạo trong DN không chỉ là đổi mới về công nghệ mà còn tập trung đến yếu tố quản trị DN. Do đó, để việc đổi mới sáng tạo trong DN đạt hiệu quả, DN cần phối hợp đồng bộ giữa đổi mới quản trị và công nghệ. Đổi mới sáng tạo trong $\mathrm{DN}$ không quan trọng quy mô hoạt động lớn hay nhỏ mà quan trọng là đổi mới sáng tạo, giúp $\mathrm{DN}$ có nhiều điều kiện để xác định điểm mạnh và điểm yếu của đơn vị mình. Từ đó, tìm giải pháp khắc phục yếu kém và phát huy điểm mạnh của DN. Trước đây, Sài Gòn Food sản xuất với quy mô khoảng vài trăm tấn thực phẩm/năm, đến nay công suất sản xuất của DN đã 
nâng lên khoảng 70.000 tấn... Đây là chính kết quả sự khát khao đổi mới sáng tạo trong $\mathrm{DN}$ và sự kêt hợp tốt giữa đổi mới về quản trị và công nghệ, góp phẩn đưa đến thành công và danh tiếng của Sài Gòn Food trên thị trường.

Ông Huỳnh Quang Vinh, Phó tổng giám đốc Công ty Cổ phần rau quả thực phẩm An Giang (Antesco), chia sẻ: "Đổi mới sáng tạo không chỉ dựa vào năng lực nội tại vốn có của $\mathrm{DN}$ mà rất cần sự trợ lực của Nhà nước. Do đó, thời gian qua, Antesco đặc biệt nghiên cứu thực hiện tốt các chính sách, chủ trương của địa phương. Ngoài ra, xác định là đơn vị chuyên sản xuất nông sản đóng hộp nên Antesco luôn chú trọng việc xây dựng mối quan hệ tốt với nông dân, xây dựng vùng nguyên liệu sạch. Song song đó, Antesco còn áp dụng các tiêu chí hợp tác nhằm chia sẻ kinh nghiệm sản xuất cho nông dân và hợp tác bao tiêu để giải quyết đầu ra cho nông sản, giúp nông dân yên tâm sản xuất, cung cấp nguồn liệu ổn định cho DN. Hiện tại, nhiều sản phẩm đóng hộp của Antesco không chỉ tiêu thụ trong nước mà còn xuất khẩu ra nước ngoài. Thời gian tới, Antesco tiếp tục đưa ra thị trường nhiều sản phẩm bổ sung, sản phẩm tốt cho sức khỏe... để khẳng định được thương hiệu, mở rộng thị trường".

Theo đại diện Công ty TNHH MTV Việt Nam Kỹ nghệ súc sản (Vissan), ở góc độ của nhà sản xuất, Vissan quyết liệt đổi mới để nâng cao chất lượng sản phẩm cho ra thị trường sản phẩm mới đảm bảo an toàn vệ sinh thực phẩm, đáp ứng nhu cầu của người tiêu dùng. Bên cạnh đó, Vissan còn chú trọng tìm kiếm kênh phân phối, kiểm soát bán lẻ, bố trí cán bộ giám sát... để chọn kênh phân phối thịnh hành. Trên cơ sở đó, giúp Vissan đáp ứng tốt nhu cầu sản lượng cũng như nhu cầu của các đại lý, điểm bán lẻ... góp phần đưa sản phẩm của Vissan phát triển vươn xa trên thị trường. Ngoài ra, Vissan còn tìm hiểu đặc trưng của từng vùng miền và thói quen mua sắm của người tiều dùng để cho ra đời những dòng sản phẩm phù hợp với thị hiếu của người tiêu dùng.

\section{Giúp DN chủ động đổi mói sáng tạo}

Bà Vũ Kim Hạnh, Chủ tịch Hội DN HVNCLC, cho biết: "Việc đổi mới sáng tạo ở những DN lớn không chỉ mang đến thành công cho $\mathrm{DN}$ này mà còn tác động đến các $\mathrm{DN}$ nhỏ và vừa, kể cả những cơ sở đặc sản làng nghề. Hội DN HVNCLC sẽ đồng hành và hỗ trợ DN từ khi có ý tưởng đổi mới đến công tác thay đồi thiết bị, máy móc và công nghệ, thay đổi hệ thống quản trị để hình thành sản phẩm". Theo bà Hạnh, năm 2014, Hội sẽ tập trung đẩy mạnh công tác hỗ trợ $\mathrm{DN}$ đồi mới sáng tạo về cồng nghệ và quản trị để $\mathrm{DN}$ phát triển và làm chủ thị trường. Chú trọng cải tiến các hoạt động xúc tiến thị trường, đưa ra những tiêu chí cụ thể trong bộ công cụ đo lường năng lực đồi mới sáng tạo, triển khai các chương trình tư vấn cho DN... Song song đó, DN cần chủ động đẩy mạnh hoạt động đổi mới sáng tạo. Đây được xem là một yếu tố quyết định sống còn, sẽ giúp DN hiểu rõ hiện trạng năng lực đổi mới sáng tạo và có những định hướng, tìm kiếm giải pháp để tăng cường sức cạnh tranh trên thị trường. 
Theo ông Trần Thiện Linh, Trưởng phòng Quản lý Sở hữu trí tuệ, Sở Khoa học và Công nghệ tỉnh An Giang, để nâng cao nhận thức và nâng cao năng lực đổi mới sáng tạo cho $\mathrm{DN}$, thời gian qua, Sở Khoa học và Công nghệ tỉnh An Giang phối hợp cùng các đơn vị có liên quan tổ chức nhiều chương trình hội thảo để tuyên truyền, trao đổi thông tin, xúc tiến các hoạt động nghiên cứu ứng dụng, đổi mới sáng tạo công nghệ, chuyển giao công nghệ và sản xuất thử nghiệm. Tổ chức các chương trình hợp tác để tìm kiếm, khảo sát, đánh giá các kỹ thuật, công nghệ mới, công nghệ tiên tiến. Đồng thời, triển khai các hoạt động hỗ trợ cho các đơn vị, tổ chức, cá nhân có nhu cầu nghiên cứu ứng dụng và chuyển giao các tiến bộ khoa học công nghệ... Trên cơ sở đó, lựa chọn mô hình phù hợp để ứng dụng và nhân rộng trên địa bàn tỉnh. Ngoài ra, tỉnh còn tạo nhiều điều kiện thuận lợi để DN thực hiện quá trình đổi mới sáng tạo công nghệ, ứng dụng có hiệu quả kết quả nghiên cứu sáng tạo để tạo ra những sản phẩm có sức cạnh tranh cao trên thị trường.

Từ năm 2003 đến năm 2013, toàn tỉnh An Giang có khoảng 8o DN được hỗ trợ thực hiện đổi mới công nghệ và có 193 giải pháp tham Hội thi sáng tạo kỹ thuật của tỉnh. Ông Trần Thiện Linh, Trưởng phòng Quản lý Sở hữu trí tuệ, Sở Khoa học và Công nghệ tỉnh An Giang, cho biết: Tỉnh An Giang đạt khá nhiều thành tựu trong đổi mới, sáng tạo trên lĩnh vực công nghệ sinh học; nuôi trồng, bảo quản và chể biến nông lâm thủy sản; mô hình tái chế, xử lý chất thải, năng lượng tái tạo và bảo vệ môi trường... Trong đó, nhiều mô hình đổi mới, sáng tạo đạt hiệu quả như: mô hình sinh sản bán nhân tạo lươn đồng; mô hình phát triển mạng lưới nhân giống lúa, nếp đạt tiêu chuẩn xuất khẩu và chống chịu tốt với rầy nâu; dự án phát triển công nghệ sản xuất và chế biến nấm rơm, nấm bào ngư; mô hình chuyển giao kỹ thuật quản lý, xử lý chất thải rắn nông thôn; mô hình xây dựng dây chuyền sản xuât gạch không nung. Những mô hình này đang được ứng dụng rộng rãi vào thực tế.

Theo bà Vũ Kim Hạnh, Nhà nước, $\mathrm{DN}$ và nhà nghiên cứu là một "tam giác" trong quy trình đổi mới sáng tạo. Trong đó, $\mathrm{DN}$ là là một góc trọng tâm của "tam giác" trong đổi mới sáng tạo. Tuy nhiên, để quy trình đổi mới sáng tạo trong DN đạt hiệu quả cần có sự tương tác hỗ trợ của các nhà nghiên cứu và Nhà nước.

\section{Theo Báo Cần Tho}


